\title{
Congenital Forearm Pseudarthrosis, a Systematic Review for a Treatment Algorithm on a Rare Condition
}

\author{
Michiel Siebelt, PhD, MD, *† Suzanne de Vos-Jakobs, MD, * Nienke Koenrades, MD, * \\ Christianne A.V. van Nieuwenhoven, PhD, MD, $\neq$ Rianne Oostenbrink, PhD, MD, $\S$ \\ Wichor M. Bramer, PhD, $\|$ Jan A.N. Verhaar, PhD, MD, * Gert J.H.J.M. Bessems, MD, * \\ and Dagmar R.J. Kempink, MD*q
}

Background: A congenital forearm pseudarthrosis is a rare condition and is strongly associated with neurofibromatosis type 1 . Several surgical techniques are described in the literature, but the most optimal treatment strategy remains unclear. This systematic review aims to develop a treatment algorithm that may aid in clinical decision making.

Methods: The PROSPERO registration number for this study was CRD42018099602 and adheres to the PRISMA guidelines for systematic reviews. Embase, MEDLINE, Cochrane Central, Web of Science, and Google Scholar databases were searched for published studies reporting on congenital forearm pseudarthrosis not related to other underlying pathologies like bacterial infection or fibrous dysplasia. Results were not restricted by date or study type, only English literature was allowed. Studies were assessed for quality using the critical appraisal checklist for case reports from the Joanna Briggs Institute. Patient characteristics, underlying disease, type of surgery, union rate, and functional outcome were extracted from included studies.

Results: Of 829 studies identified, 47 were included in this review (17 case series and 30 case reports, a total of 84 cases). A onebone forearm procedure showed highest union rates $(92 \%)$, however, it results in loss of forearm rotation. Free vascularized fibula grafting showed high union rates $(87 \%)$ and was related to good functional outcome of elbow flexion and forearm rotations. Other procedures showed disappointing outcomes.

Conclusions: Congenital forearm pseudarthrosis is best treated with a free vascularized fibula grafting, a one-bone forearm

From the Departments of *Orthopedic Surgery; $₫$ Plastic and Reconstructive Surgery; §Pediatrics and ENCORE-NF1 Centre of Expertise; \|Biomedical Information, Erasmus Medical Centre, Rotterdam; †Department of Orthopedic Surgery, St Anna Hospital, Geldrop; and $\uparrow$ Department of Orthopedic Surgery, Leiden University Medical Centre, Leiden, The Netherlands.

The authors have no financial disclosures.

The authors declare no conflicts of interest.

Reprints: Michiel Siebelt, PhD, MD, Department of Orthopedic Surgery, St Anna Hospital, P.O. Box 90, 5660 AB Geldrop, The Netherlands. E-mail: m.siebelt@st-anna.nl.

Supplemental Digital Content is available for this article. Direct URL citations appear in the printed text and are provided in the HTML and PDF versions of this article on the journal's website, www. pedorthopaedics.com.

Copyright (C) 2019 Wolters Kluwer Health, Inc. All rights reserved.

DOI: $10.1097 /$ BPO.0000000000001417

procedure should be used as a salvage procedure. Evidence extracted from the case reports was sufficient to generate a treatment algorithm to be used in clinical pediatric practice.

Level of Evidence: Level IV—-therapeutic.

Key Words: congenital pseudarthrosis, dysplasia, neurofibromatosis (J Pediatr Orthop 2020;40:e367-e374)

Conge ongenital forearm pseudarthrosis is a rare condition. Cheng et $\mathrm{a}^{1}{ }^{\mathrm{r}}$ reported an incidence of congenital forearm pseudarthrosis of 2 cases in a general population of 1 million people over a 10 -year period. There seems to be no racial or demographic predisposition for this condition. ${ }^{1}$ From 1920 to 1940, Tillier, Ducroquet, Barber, and Moore were among the first to report on the frequency of neurofibromas and café-au-lait spots in association with congenital pseudarthrosis. ${ }^{2}$ These symptoms are distinctive features for neurofibromatosis type 1 (NF1) (ie, von Recklinghausen disease). ${ }^{3}$ From the 1960 s the possible relation between NF1 and congenital pseudarthrosis was further established, ${ }^{4}$ and café-au-lait have been reported to be present in $69 \%$ of the pseudarthrosis cases. ${ }^{5}$

Historically, patients with a congenital dysplasia or pseudarthrosis usually present with a progressive deformity of the arm from birth. Or they present after a (minor) trauma that may already have been unsuccessfully treated with cast immobilization or open reduction and internal fixation (ORIF). Plain radiographs show an osseous lesion that can be described using several classification systems. ${ }^{6,7}$ Crawford and Bagamery ${ }^{8}$ described different subtypes of congenital pseudarthrosis and distinct characteristics like a failure of tubularization, cystic enlargement, and frank pseudarthrosis with "sucked candy" narrowing of the end of the involved bone. Progressive bowing of the forearm may develop with loss of wrist and elbow function, loss of grip strength, and (sub) luxation of the radiocapitellar joint.

Treatment for this condition is challenging, especially since it develops in a growing child. Primary requirements for treatment are: successful pseudarthrosis union, stabilization of the forearm joints [the distal radioulnar joint (DRUJ), ulnocarpal joint, and radiocapitellar joint], and 
continued skeletal growth., ${ }^{9,10}$ Multiple surgical strategies for congenital pseudarthrosis of the forearm have been described in the literature. There are reports on ORIF, either with or without autogenous bone grafting, external fixation, free vascularized fibula grafting (FVFG), and radioulnar fusion into a one-bone forearm (OBF). Because of its rarity, only a few case reports and case series describe this condition. No large cohort studies or randomized trials are available.

In 2013, Stevenson et $\mathrm{a}^{11}$ reported a consensus report on the treatment of an NF1-related tibial pseudarthrosis, but guidelines for the treatment of congenital forearm pseudarthrosis are lacking. Therefore, the aim of this systematic review was to define a treatment protocol for patients with an NF1 or idiopathic-related congenital forearm pseudarthrosis (either radius, ulna, or both bone), not related to other known pathology (eg, fibrous dysplasia). Through a systematic search, we aim to discuss which treatment strategies are best, on the basis of union rates and functional outcome. Furthermore, we propose a guideline that may aid the clinician during the initial patient assessment, preoperative work-up, and selection of surgical strategy. Furthermore, we will address the postoperative follow-up and management of complications.

\section{METHODS}

\section{Study Protocol and Registration}

Before start of this systematic review, the aim and study protocol was published online using PROSPERO (CRD42018099602).

\section{Search Strategy}

In this systematic review, we searched 5 databases (Embase, MEDLINE, the Cochrane library, Web of Science, and Google Scholar) in cooperation with a medical information specialist (W.M.B.) to identify relevant studies related to congenital forearm pseudarthrosis. We included all forms of published studies (clinical trial, cohort, cross-sectional, case series, and case reports) that report on congenital forearm pseudarthrosis, without any limit to a year of publication. We excluded studies written in any other language than English. The search was executed on March 13, 2018.

The full electronic search strategy for Embase was: ["pseudarthrosis"/exp OR ("fracture nonunion"/de AND ("congenital disorder"/de OR "neurofibromatosis"/exp)] OR \{pseudarthros* OR pseudoarthros* OR pseud*arthros* OR [(nonunion* OR non-union*) NEAR/6 (neurofibromat* OR congenit*)]\}:ab,ti) AND ("ulna"/exp OR radius/exp OR "ulna fracture"/exp OR "radius fracture"/ exp OR "forearm"/de OR "forearm injury"/de OR "forearm fracture"/de OR (ulna OR ulnar OR forearm* OR fore-arm* OR radius):ab,ti) NOT ([animals]/lim NOT [humans]/lim) AND [english]/lim NOT ([Conference Abstract]/lim) NOT (adult/exp NOT (juvenile/exp OR pediatrics/exp)). Searches for the other reported databases can be found as supplementary data online (Supplemental Digital Content 1, http://links.lww.com/BPO/A228).
Two authors (M.S., S.d.V.-J.) independently reviewed titles and abstracts of the list of studies identified by the search to select those that fulfilled the selection criteria: congenital forearm dysplasia, all treatment modalities were eligible, not tumor related, not infection related, not related to fibrous dysplasia. Disagreement on study eligibility was resolved by consensus, with reference to a third author (D.R.J.K.) if required. After this selection procedure, we retrieved full texts of the selected titles.

\section{Data Collection and Analysis}

As mentioned before, most data on this topic are presented in case reports or case series. These observational studies typically yield very low quality of evidence according to the GRADE guidelines. In order to still asses for quality, we used the checklist for case reports from the Joanna Briggs Institute. ${ }^{12}$ Five authors (M.S., S.d.V.-J., N.K., G.J.H.J.M.B., D.R.J.K.) independently scored all included articles for quality according to this checklist. Disagreement on study quality was resolved by consensus.

Two authors (M.S., S.d.V.-J.) independently extracted data on the number of patients, age on presentation, family history related to NF1, clinical presentation related to NF1, involved bone of pseudarthrosis (radius, ulna, both bone), underlying disease, histology outcome, cast application and union rate, surgical interventions and union rate, and clinical outcome of elbow and forearm function. Because of the large heterogeneity in reporting in elbow and forearm function, this outcome was recorded as either: full range of motion (FROM) as compared with the contralateral side, functional with minor limitations ( $>2 / 3$ of FROM), major functional limitations ( $<2 / 3$ of FROM).

The low methodological quality of the original studies limits meaningful statistical comparison. Therefore, all data will be discussed using a descriptive approach.

\section{Source of Funding}

There was no external funding source for this study, nor any sort of funding that could influence the design or outcome of this study.

\section{RESULTS}

After the screening of 829 potentially relevant studies, we identified 70 articles which we tried to retrieve in full text. One article could not be retrieved (Tamai et al). ${ }^{13}$ After reading the remaining 69 full-text articles, 47 were included for this review (Fig. 1). None of the included articles discuss long-term follow-up (5 or $10 \mathrm{y}$ followup data).

Table 1 shows the demographics of the data synthesis results. From the included 47 studies, 84 cases were included (22 radii, 44 ulnae, 18 both bone pseudarthrosis). There was a slight male predominance (males $50 \%$, females $36 \%$, sex unclear $14 \%$ ). Most patients either presented with a progressive deformity $(51 \%)$ or posttraumatic $(32 \%)$. In $74 \%$ of all cases, neurofibromatosis was identified as the underlying disease. 


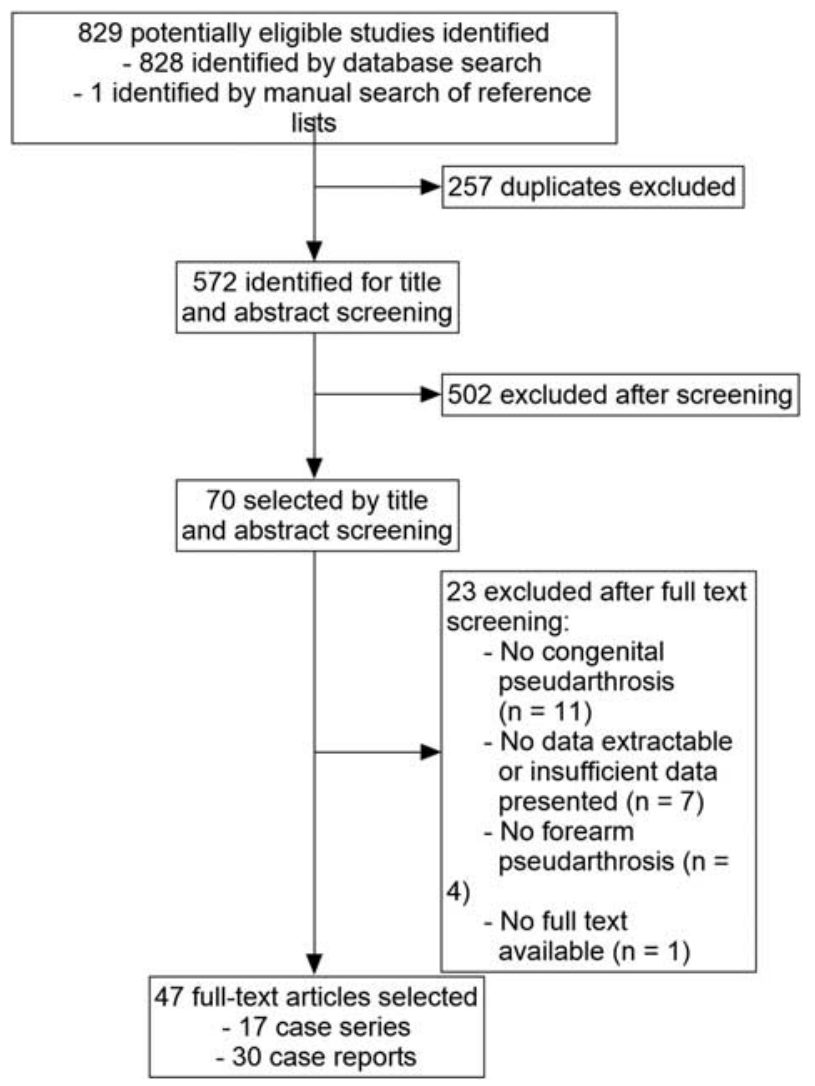

FIGURE 1. Flow diagram for inclusion and exclusion of articles for this systematic review.

DNA reporting was lacking, however, and there was poor reporting on positive family history $(21 \%)$ or skin changes (41\%). Cast treatment was applied in $45 \%$ of all cases, which led to a successful union in only 1 patient.

Of all 84 cases, 1 patient was without complaints and no further treatment was initiated. ${ }^{5}$ In 9 patients, the surgical procedure was not specified and no records regarding union were described. ${ }^{14-22}$ Table 2 describes the pooled results of all reported surgical attempts in the remaining 74 patients. One hundred eight procedures could be categorized into: osteosynthesis procedures, ${ }^{23-26,29,32}$ osteosynthesis procedure combined with nonvascular bone grafting, $2,5,14,16,23,30,33,35-39,43,44,46$ use of external fixation, ${ }^{34,45,49}$ use of a FVFG transfer, $1,5,9,10,27,28,34,40-42,47,48,50-52,56$ radioulnar fusion into a $\mathrm{OBF}, 1,5,14,20,31,44,53,54$ and use of a FVFG transfer for creation of a OBF. ${ }^{48,55}$

Reports on the final clinical function were poor among the included studies. In $31(42 \%)$ patients no comments regarding elbow function were made, forearm rotation was not reported in $34(46 \%)$ patients. Clinical outcome was best reported in the FVFG group. After FVFG, in 24 of 30 patients showed either a FROM or sustained only a minor limitation related to elbow flexion $(80 \%)$ (Table 3). Forearm rotations in 18 of 30 FVFG patients showed either a FROM or was restricted to a minor extent $(60 \%)$. For OBF patients, 11 patients $(92 \%)$
TABLE 1. Demographic Characteristics of all Included Cases With a Congenital Forearm Pseudoarthrosis

\begin{tabular}{lcc}
\hline & Number (\%) & $\begin{array}{c}\text { Age } \\
\text { (Mean } \pm \text { SD) }\end{array}$ \\
\hline No. cases & 84 & \\
Sex & & \\
Male & $42(50)$ & $5.9 \pm 4.2$ \\
Female & $30(36)$ & $4.9 \pm 3.8$ \\
Sex unclear & $12(14)$ & - \\
Complaint & $43(51)$ & $4.5 \pm 4.7$ \\
Deformity & $27(32)$ & $5.6 \pm 3.8$ \\
Trauma & $4(5)$ & $5.8 \pm 4.3$ \\
Other & $10(12)$ & - \\
Unclear & $22(26)$ & \\
Affected bone & $44(53)$ & \\
Radius & $18(21)$ & \\
Ulna & & \\
Both bones & $62(74)$ & \\
Underlying pathology & $13(21)$ & \\
Neurofibromatosis 1 & $41(66)$ & \\
$\quad$ Positive family history & & \\
$\quad$ Skin changes (eg, café-au-lait & $22(26)$ & \\
$\quad$ spots) Histology reported & $6(27)$ & \\
$\quad$ Histology reported & $15(68)$ & \\
$\quad$ Positive for NF1 & $1(5)$ & \\
$\quad$ Nonspecific & $5(6)$ & \\
Unknown & $17(20)$ & \\
Idiopathic & $38(45)$ & \\
Unclear & $10(12)$ & \\
Prior cast treatment & $36(43)$ & \\
Yes & & \\
No & & \\
Unclear & & \\
\hline$\quad$ & & \\
& &
\end{tabular}

showed a FROM in regards to elbow flexion or sustained only a minor limitation (Table 3). Limited information about forearm rotations were mentioned in the included studies that present OBF patients. However, as rotations are lost after this procedure, authors are likely not to report on rotations. For both FVGF and OBF, the most frequent described complication was forearm shortening $(\mathrm{n}=12)$ and was mostly managed by a within graft lengthening procedure.

\section{DISCUSSION}

This systematic review covers the literature reported on congenital forearm pseudarthrosis, which is a rare condition associated with NF1. In this discussion, we propose a guideline for the management of this rare entity (Fig. 2). The major limitation for this systematic review is that included studies were predominant case reports and case series, and reduces the level of evidence. However, because of its rarity no large cohort studies are likely to be published, and data from case reports and case series are the only source to pursue therapeutic improvement for these patients. However, the quality of the reported data was poor. All but one of the included articles were published before the publication of guidelines for surgical case reports (SCARE guidelines), ${ }^{57}$ and publication of guidelines for preferred reporting of case series in surgery (PROCESS guidelines). ${ }^{58}$ This might explain why most 
TABLE 2. Pooled Results for all Surgical Procedures Related to Pseudarthrosis Union

\begin{tabular}{lcccc}
\hline & & \multicolumn{2}{c}{ Union (\%) } & \\
\cline { 3 - 4 } Treatment & $\mathbf{N}$ & Yes & No & References \\
\hline Osteosynthesis & 13 & $3(23)$ & $10(77)$ & \\
$\quad$ Plate & $6(46 \%)$ & $2(33)$ & $4(67)$ & $23-28$ \\
K wires & $3(23 \%)$ & $0(0)$ & $3(100)$ & $29-31$ \\
Intramedullary nailing & $4(31)$ & $1(25)$ & $3(75)$ & $28,32-34$ \\
Bone grafting & 46 & $16(35)$ & $30(65)$ & \\
Iliac crest & $17(37 \%)$ & $7(41)$ & $10(59)$ & $5,10,30,33,35-42$ \\
Tibia & $8(17 \%)$ & $2(25)$ & $6(75)$ & $14,39,43$ \\
Fibula & $5(11 \%)$ & $1(20)$ & $4(80)$ & $5,14,23,44$ \\
Allogenic & $2(4 \%)$ & $0(0)$ & $2(100)$ & 5,45 \\
Unknown & $14(31 \%)$ & $6(43)$ & $8(57)$ & $2,5,9,16,25,28,43,46-49$ \\
External fixation & 3 & $3(100)$ & $0(0)$ & $34,45,49$ \\
FVFG & 31 & $27(87)$ & $4(13)$ & \\
Plate & $14(45 \%)$ & $12(86)$ & $2(14)$ & $5,9,10,47,48,50$ \\
K wires/screw & $12(39 \%)$ & $10(83)$ & $2(17)$ & $1,9,28,40,42,48,51,52$ \\
Intramedullary nail & $4(13 \%)$ & $4(100)$ & $0(0)$ & $27,34,48,52$ \\
Without osteosynthesis & $1(3 \%)$ & $1(100)$ & $0(0)$ & 41 \\
OBF & 12 & $11(92)$ & $1(8)$ & $1,5,14,20,31,44,53,54$ \\
FVFG used for OBF & 3 & $3(100)$ & $0(0)$ & 48,55 \\
\hline
\end{tabular}

This table shows the pooled results of all reported surgical attempts $(n=108)$ in the remaining 74 patients.

FVFG indicates free vascularized fibula graft; OBF, one-bone forearm.

reports were of arguable quality. With data extraction from these published papers, we do feel that we were able to generate a valid treatment algorithm that could be of interest for clinicians confronted with this pathology.

\section{Clinical Presentation and Work-up}

Patients initially often present with a deformity $(51 \%)$ or after a (mild) trauma $(32 \%)$ with a persisting fracture (Table 1). Many pseudarthrosis patients that initially presented after trauma are likely to have undergone previous treatment, like casting $(45 \%)$ or even ORIF. Successful union rates of both treatments are low (cast 3\%; ORIF 23\%). Every surgeon confronted with persisting nonunion of a forearm fracture after an initial cast or surgical management (Fig. 2), should be aware of possible underlying (NF1) pathology given the fact that congenital forearm pseudarthrosis is mostly NF1 related $(74 \%)$.

It is important to discriminate the pseudarthrosis lesion from other tumorous lesions. For example, a patient with a fibrous dysplasia has a much better prognosis and a different treatment approach is necessary. ${ }^{15,59}$ Data from this systematic review shows that 5 cases $(6 \%)$ were considered idiopathic and in 17 cases $(20 \%)$ the underlying pathology remained unclear. We believe that a large portion of these cases is also NF1 related, but proper diagnostic studies were either not performed or not reported on. Mostly histology is mentioned as a diagnostic tool for NF1. This was reported for $26 \%$ of the cases and from these 22 patients, only $6(27 \%)$ proved underlying NF1 pathology. These low numbers are in line with other reports investigating neurofibromatosis in histology specimens. ${ }^{15,60}$ In our opinion, a surgical biopsy for diagnosis through histology is therefore not justified. The included studies did not mention other diagnostic tools like DNA studies, which can be beneficial to further establish the correct diagnosis. ${ }^{61}$ It should be noted, however, that $5 \%$ to $10 \%$ of patients with NF are not detected by DNA testing. ${ }^{62}$ However, a thorough diagnostic approach including clinical and ophthalmologic investigation combined with DNA testing will further establish a relation with NF1 and congenital forearm pseudarthrosis. We advocate additional referral to an ophthalmologist and pediatrician for further diagnosis of underlying NF1.

After a possible relation with NF1 is established, the physical examination is most important for further treatment of the congenital pseudarthrosis. Casting should not be attempted to achieve union, but should only be considered to reduce further bowing and prevent (sub)luxation of the radiocapitellar joint and functional loss. ${ }^{20,53}$ Patients with a proximal deformity or pseudarthrosis are less likely to suffer from progressive bowing and therefore good candidates for nonoperative cast treatment. ${ }^{17}$ Preliminary abnormalities (eg, dysplasia) with normal function and strength of elbow, forearm, and wrist, could initially be

TABLE 3. Pooled Results for Functional Outcome Related to all Surgical Procedures

\begin{tabular}{|c|c|c|c|c|c|c|c|c|c|c|}
\hline \multirow[b]{3}{*}{$\begin{array}{l}\text { Treatment } \\
\text { Related to } \\
\text { Functional } \\
\text { Outcome }\end{array}$} & \multirow[b]{3}{*}{$\mathbf{N}$} & \multicolumn{8}{|c|}{ Functional Outcome [n (\%)] } & \multirow[b]{3}{*}{ References } \\
\hline & & \multicolumn{4}{|c|}{ Elbow (Flexion/Extension) } & \multicolumn{4}{|c|}{ Forearm (Pronation/Supination) } & \\
\hline & & FROM & $\begin{array}{c}\text { Functional } \\
\text { Elbow With } \\
\text { Minor } \\
\text { Limitations }\end{array}$ & $\begin{array}{c}\text { Elbow With } \\
\text { Major } \\
\text { Functional } \\
\text { Limitations }\end{array}$ & Unknown & FROM & $\begin{array}{c}\text { Functional } \\
\text { Forearm } \\
\text { With Minor } \\
\text { Limitations }\end{array}$ & $\begin{array}{c}\text { Forearm } \\
\text { With Major } \\
\text { Functional } \\
\text { Limitations }\end{array}$ & Unknown & \\
\hline Osteosynthesis & 6 & $1(17)$ & $1(17)$ & - & $4(67)$ & $1(17)$ & - & $1(17)$ & $4(67)$ & $21-24,29,32$ \\
\hline FVFG & 30 & $15(50)$ & $9(30)$ & - & $6(20)$ & $6(20)$ & $12(40)$ & $6(20)$ & $6(20)$ & $1,5,9,27,34,40-42,45,47-52,56$ \\
\hline OBF & 12 & $6(50)$ & $5(42)$ & - & $1(8)$ & - & $3(25)$ & $3(25)$ & $6(50)$ & $1,5,11,18,28,46,53,54$ \\
\hline $\begin{array}{l}\text { FVFG used for } \\
\text { OBF }\end{array}$ & 3 & $2(66)$ & - & - & $1(33)$ & - & - & $3(100)$ & $0(0)$ & 31,50 \\
\hline
\end{tabular}

Because of the large heterogeneity in reporting of the elbow and forearm function, this outcome was recorded as either: full range of motion (FROM), functional with minor limitations $(>2 / 3$ of FROM), major functional limitations $(<2 / 3$ of FROM).

FVFG indicates free vascularized fibula graft; OBF, one-bone forearm. 


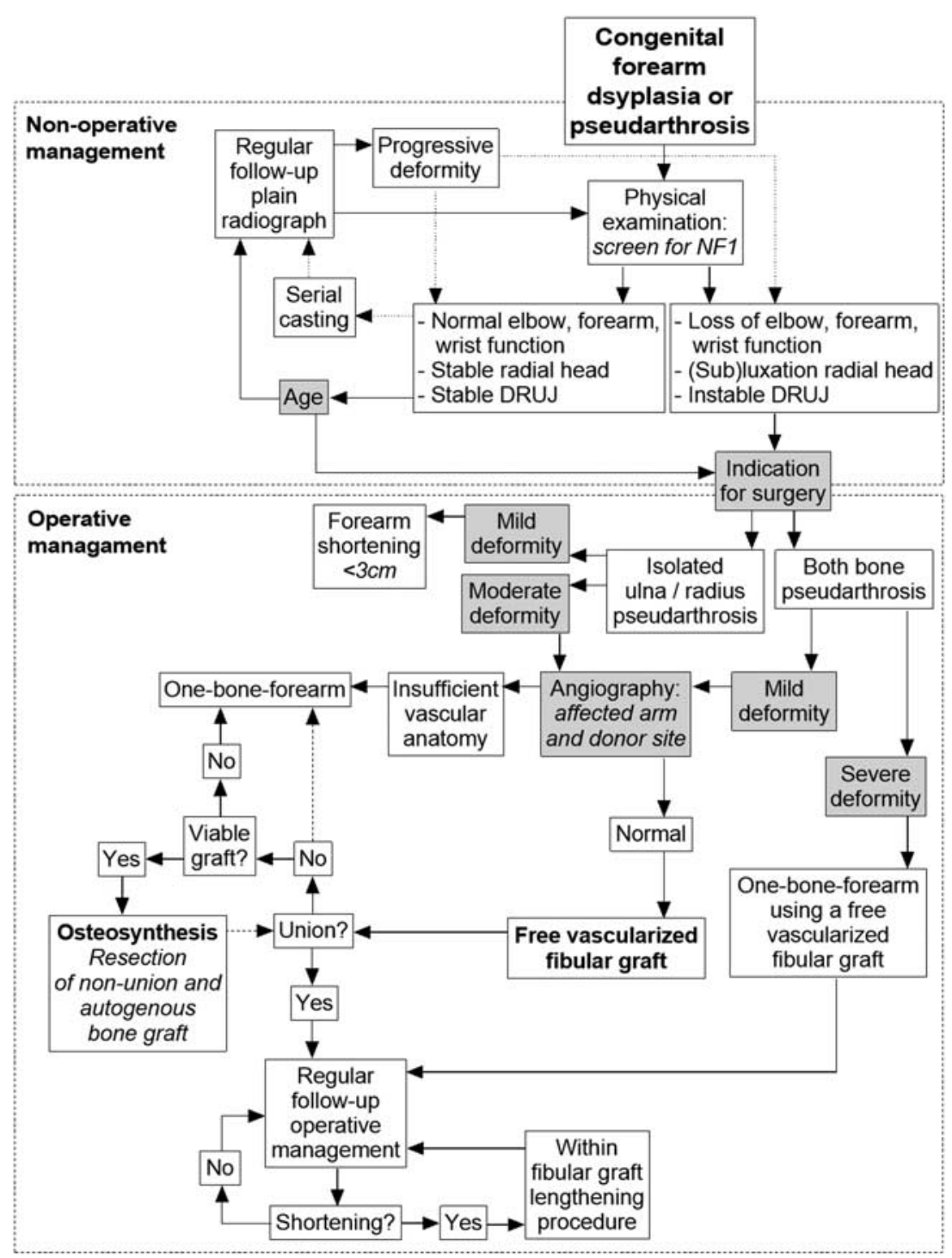

FIGURE 2. Flowchart for treatment of congenital pseudarthrosis of the forearm. The gray boxes represent a clinical decision which is still debated, these points are more extensively addressed in the discussion. DRUJ indicates distal radioulnar joint; NF1, neurofibromatosis type 1 .

treated nonoperatively using serial casting (Fig. 2). ${ }^{20,47}$ During this nonoperative management, patients have to be monitored regularly with serial physical examination and repeated plain radiographs.

\section{Indication for Surgery}

Progressive deformities in congenital forearm pseudarthrosis often lead to impaired wrist and elbow function. It is stated that the ulna makes the elbow and the radius makes the wrist. ${ }^{63}$ Pseudarthrosis of the radius is likely to induce DRUJ instability, and pseudarthrosis of the ulna is associated with instability of the radiocapitellar joint. For the latter, it is thought that tethering of the ulna and normal growth of the radius, leading to increased pressure on the lower humeral epiphysis may cause impaired development of the capitellum and trochlea, making the radiohumeral joint unstable. ${ }^{23}$ In all untreated ulnar pseudarthrosis, radial head dislocation is likely to occur. ${ }^{1}$ The vast majority of cases with untreated congenital ulnar pseudarthrosis above 1 year of age are associated with lateral dislocation of the radial head and degeneration of the radiocapitellar joint. ${ }^{5}$ Furthermore, chronic radial head dislocation leads to increasing valgus deformity of the elbow and may induce subsequent ulnar or radial nerve disturbance. ${ }^{64,65}$ Presence of joint instability and loss of function are clear indications for operative management.

In the reviewed literature, there is no clear consensus on whether patients without complaints should be operated on. From NF1-related tibia pseudarthrosis, it is known that age is a factor that influences union outcomes. $^{7}$ Older reports state that surgery should be postponed until skeletal maturity. ${ }^{30,33}$ However, these 
authors used bone grafting and osteosynthesis as a treatment modality. This has poor union rates $(35 \%)$. FVFG shows more successful union rates (87\%), in articles concerning FVFG surgery at a younger age, is advocated. For example, Allieu et $\mathrm{al}^{55}$ report that surgical treatment should be performed as early as possible to minimize epiphyseal involvement and abnormal growth. More recently, Bauer et al ${ }^{47}$ propose to utilize surgery before 3 years of age in order to avoid further progression of pseudarthrosis and deformity (Fig. 2). In the line with these reports, we suggest that nonoperatively treated patients should be closely monitored. Serial casting can be continued in rare cases that patients remain clinically well (no loss of function, no radial head (sub)luxation, no DRUJ instability), are without radiologic progression of pseudarthrosis and progression of the deformity is limited. Follow-up should be intensified after 3 years of age, as the loss of function and bowing can be more progressive and surgery should be considered more easily.

\section{Surgical Management}

Historically, it is difficult to acquire union of the pseudarthrosis and various treatment methods have been described. Union rates of cast immobilization, osteosynthesis, cortico-cancellous autologous bone grafting in congenital pseudarthrosis patients have shown to be rather disappointing and should be disregarded as a treatment option (Table 2). Only in rare cases with very mild deformities, resection can be considered if the forearm shortening does not exceed $3 \mathrm{~cm}^{34,36}$ (Fig. 2). Other techniques, like FVFG and radioulnar fusion into a OBF show improved fusion rates (respectively $87 \%$ and $92 \%)$.

As FVFG has good union rates (Table 2) and good clinical outcome (Table 3) this procedure is central for the treatment of congenital forearm pseudarthrosis (Fig. 2). There are several reports that provide an excellent detailed description of the operative technique. ${ }^{10,47}$ Some authors report the use of angiography of both donor site and graft site, in order to check the vascular status. ${ }^{10,27,28,41}$ However, Bauer et al ${ }^{47}$ reported not to routinely perform this evaluation but stated that when the surgeon has concerns about the vascularity or the child has undergone prior surgery in the area that makes the blood supply questionable, angiography can be performed. Patients with insufficient vascular supply should be treated with an OBF (Fig. 2). Graft fixation in FVFG can be achieved by using several techniques (Table 1). In our opinion, $\mathrm{K}$ wire fixation is the best alternative which allows for fixation without damaging vascular supply. ${ }^{42}$ Furthermore, a valgus deformity at the ankle because of proximal migration of the lateral malleolus is a common complication. Allieu et $\mathrm{al}^{27}$ advocate fusion of the distal fibula to the distal tibia, in order to prevent valgus deformity after harvesting the distal fibula for FVFG. ${ }^{10}$

Moreover, an OBF removes the restraining effect of the pseudarthrosis. After this procedure, the humeroulnar and radiocapitellar joints remain functional and proper elbow and hand function is anticipated. ${ }^{20}$ The major difference between OBF and FVFG, is that FVFG does not impair forearm rotation and an OBF does not. ${ }^{23}$ In this review, we found the good clinical outcome in $58 \%$ of FVFG-treated patients. For OBF patients, there were 3 patients $(25 \%)$ for who only minor functional limitations were mentioned. However, exact reports in degrees of motion were lacking and is likely they need compensatory movements because of restricted forearm rotation. Therefore, the OBF should be considered to be a salvage procedure, for cases that are not considered for an FVFG. For patients with involvement of the ulna and radius, a combination of both procedures can be considered, in which an FVFG is used to create an OBF (Table 2). ${ }^{48,55}$

For both procedures, several aspects are important for a good outcome. First, the abnormal surrounding soft tissues in congenital forearm pseudarthrosis are known to have an important role in the establishment and maintenance of the condition. ${ }^{29}$ Therefore, wide surgical resection is of utmost importance. ${ }^{34,66}$ Especially an FVFG allows for proper wide resection and bridging of the remaining defect, without increasing risk for nonunion. ${ }^{42}$ However, a surgeon should always estimate whether there is sufficient length of the vascularized graft to bridge the bony defect after wide resection. If there are concerns of this sort, an OBF might be warranted. Among NF1 patients, bone involvement may vary widely and a preoperative magnetic resonance imaging might help to estimate to what extent the surgical resection should be performed. However, only a few papers mention the use of magnetic resonance imaging of bone scintigraphy in their workup. Second, in case of radiohumeral instability, an open wedge osteotomy in the ulna in order to restore ulna length can be considered ${ }^{64,67}$ with or without annular ligament reconstruction, ${ }^{59,61}$ should be considered to properly reduce the radial head and prevent future degeneration of the radiocapitellar joint. ${ }^{5}$ However, specific timing when a radiohumeral stabilization procedure should be performed is not mentioned in the papers included for this systematic review and should be further reported on.

\section{Follow-up}

During follow-up, serial radiographs should show proper union. If not, one may attempt to perform a resection of the pseudarthrosis in combination with (plate) osteosynthesis and autogenic bone grafting. ${ }^{9,47}$ If this attempt fails, or the transplanted fibular graft fails, the literature describes conversion to an $\mathrm{OBF}$ procedure as the best procedure with a predictable good functional outcome. However, this decision should be made after careful evaluation of why the first FVFG failed and whether other surgical options remain. All patient after a transplanted fibular graft should be monitored regularly. A frequently seen complication is shortening of the transplanted graft. $28,42,47,48$ This may be dealt with a through lengthening procedure within the transplanted (fibular) graft. ${ }^{52}$ 


\section{CONCLUSIONS}

Most important in the management of congenital pseudoarthrosis is to make a proper distinction with other underlying pathology than NF1. Operative management is warranted in case of loss of function and joint instability. In the case of moderate deformity, an FVFG is the most promising technique with an $\mathrm{OBF}$ as a reliable alternative.

\section{REFERENCES}

1. Cheng JCY, Hung LK, Bundoc RC. Congenital pseudarthrosis of the ulna. J Hand Surg. 1994;19 B:238-243.

2. Moore JR. Delayed autogenous bone graft in the treatment of congenital pseudarthrosis. J Bone Joint Surg Am. 1949;31A:23-39.

3. [No authors listed]. Neurofibromatosis. Conference Statement. National Institutes of Health Consensus Development Conference. Arch Neurol. 1988;45:575-578.

4. Vitale MG, Guha A, Skaggs DL. Orthopaedic manifestations of neurofibromatosis in children: an update. Clin Orthop Relat Res. 2002;401:107-118.

5. Bell DF. Congenital forearm pseudarthrosis: report of six cases and review of the literature. J Pediatr Orthop. 1989;9:438-443.

6. Andersen KS. Congenital pseudarthrosis of the leg. Late results. J Bone Joint Surg Am. 1976;58:657-662.

7. Boyd HB. Pathology and natural history of congenital pseudarthrosis of the tibia. Clin Orthop Relat Res. 1982;166:5-13.

8. Crawford AH Jr, Bagamery N. Osseous manifestations of neurofibromatosis in childhood. J Pediatr Orthop. 1986;6:72-88.

9. El Hage S, Ghanem I, Dagher F, et al. Free vascularized fibular flap for congenital ulnar pseudarthrosis: a report of two cases and review of the literature. Ann Plast Surg. 2009;62:329-334.

10. Bae DS, Waters PM, Sampson CE. Use of free vascularized fibular graft for congenital ulnar pseudarthrosis: surgical decision making in the growing child. J Pediatr Orthop. 2005;25:755-762.

11. Stevenson DA, Little D, Armstrong L, et al. Approaches to treating NF1 tibial pseudarthrosis: consensus from the Children's Tumor Foundation NF1 Bone Abnormalities Consortium. J Pediatr Orthop. 2013;33:269-275.

12. Moola S, Munn Z, Tufanaru C, et al. Chapter 7: systematic reviews of etiology and risk. In: Aromataris E, Munn Z, eds. Joanna Briggs Institute Reviewer's Manual. The Joanna Briggs Institute; 2017.

13. Tamai S, Sakamoto H, Hori Y. Vascularized fibula transplantation: a report of 8 cases in the treatment of traumatic bony defect or pseudarthrosis of long bones. Int J Microsurg. 1980;2:205-212.

14. Bayne LG. Congenital pseudarthrosis of the forearm. Hand Clin. 1985;1:457-465.

15. Brown GA, Osebold WR, Ponseti IV. Congenital pseudarthrosis of long bones. A clinical, radiographic, histologic and ultrastructural study. Clin Orthop Relat Res. 1977;128:228-242.

16. Cleveland RH, Gilsanz V, Wilkinson RH. Congenital pseudarthrosis of the radius. Am J Roentgenol. 1978;130:955-957.

17. Craigen MAC, Clarke NMP. Familial congenital pseudarthrosis of the ulna. J Hand Surg. 1995;20B:331-332.

18. Fernandez GN. Pseudarthrosis of the ulna and osteoarthritis of the elbow: a case report. J Bone Jt Surg Ser B. 1986;68:574-576.

19. Greenberg LA, Schwartz A. Congenital pseudarthrosis of the distal radius. South Med J. 1975;68:1053-1054.

20. Maffulli N, Fixsen JA. Pseudoarthrosis of the ulna in neurofibromatosis. A report of four cases. Arch Orthop Trauma Surg. 1991;110:204-207.

21. Richin PF, Kranik A, Van Herpe L, et al. Congenital pseudarthrosis of both bones of the forearm. A case report. J Bone Joint Surg Am. 1976;58:1032-1033.

22. Sprague BL, Brown GA. Congenital pseudarthrosis of the radius. J Bone Joint Surg Am. 1974;56:191-194.

23. Ali MS, Hooper G. Congenital pseudarthrosis of the ulna due to neurofibromatosis. J Bone Jt Surg Ser B. 1982;64:600-602.

24. Herring JA. Congenital pseudoarthrosis of the radius. $J$ Pediatr Orthop. 1985;5:367-369.

25. Yin Y, Rotman MB, Gilula LA. A 9-year-old girl with a bowed right forearm 6 months after a fracture. Am J Orthop. 1995;24:717, $720-722$.
26. Younge D, Arford C. Congenital pseudarthrosis of the forearm and fibula. A case report. Clin Orthop Relat Res. 1991;265:277-279.

27. Allieu Y, Gomis R, Yoshimura M. Congenital pseudarthrosis of the forearm - two cases treated by free vascularized fibular graft. $J$ Hand Surg. 1981;6:475-481.

28. Yenidunya MO, Demirseren ME, Gorkem S, et al. Reconstruction of the wrist pseudoarthrosis due to radioulnar fractures with vascularized fibular graft in a child with neurofibromatosis. Eur $J$ Plast Surg. 2007;29:327-330.

29. Gregg PJ, Price BA, Ellis HA, et al. Pseudarthrosis of the radius associated with neurofibromatosis. A case report. Clin Orthop Relat Res. 1982;171:175-179.

30. Kameyama O, Ogawa R. Pseudarthrosis of the radius associated with neurofibromatosis: report of a case and review of the literature. J Pediatr Orthop. 1990;10:128-131.

31. Lloyd-Roberts GC. Treatment of defects of the ulna in children by establishing cross-union with the radius. J Bone Joint Surg Br. 1973;55:327-330

32. Talab YA. Congenital pseudoarthrosis of the radius: a case report and review of the literature. Clin Orthop Relat Res. 1993;291:246-250.

33. Manske PR. Forearm pseudarthrosis-neurofibromatosis. Clin Orthop Relat Res. 1979;139:125-127.

34. Ramelli GP, Slongo T, Tschäppeler H, et al. Congenital pseudarthrosis of the ulna and radius in two cases of neurofibromatosis type 1 . Pediatr Surg Int. 2001;17:239-241.

35. Cobb N. Neurofibromatosis and pseudarthrosis of the ulna. A case report. J Bone Joint Surg Br. 1968;50:146-149.

36. Hayashi S, Kobayashi D, Satsuma S, et al. Acquired pseudarthrosis of the radius and ulna in a neurofibromatosis patient with radiographic normal bone: a case report. J Hand Surg. 2005;30:168-171.

37. Kaempffe FA, Gillespie R. Pseudarthrosis of the radius after fracture through normal bone in a child who had neurofibromatosis. A case report. J Bone Joint Surg Am. 1989;71:1419-1421.

38. Mollan RAB, Baird DC St. Pseudarthrosis of the radius. $J$ R Coll Surg Edinburgh. 1976;21:376-377.

39. Shertzer JH, Bickel WH, Stubbins SG. Congenital pseudarthrosis of the ulna. Report of two cases. Minn Med. 1969;52:1061-1066.

40. Ding DY, LaMartina J, Tai C, et al. Congenital pseudoarthrosis of the distal radius treated with physeal-sparing double-barrel vascularized free fibula transfer: a case report. Hand. 2017;12:NP140-NP144.

41. Williamson DM, Copeland SA, Landi A. Pseudarthrosis of the radius treated by free vascularised bone graft. J Hand Surg Br. 1989:14:221-225.

42. Witoonchart K, Uerpairojkit C, Leechavengvongs S, et al. Congenital pseudarthrosis of the forearm treated by free vascularized fibular graft: a report of three cases and a review of the literature. J Hand Surg Am. 1999;24:1045-1055.

43. Rajaratnam K, Shanker J, Varughese S. Pseudarthrosis of the ulna due to neurofibromatosis: a case report. Injury. 1989;20:239-240.

44. Ostrowski DM, Eilert RE, Waldstein G. Congenital pseudarthrosis of the ulna: a report of two cases and a review of the literature. J Pediatr Orthop. 1985;5:463-467.

45. Atar D, Lehman WB, Posner M, et al. Ilizarov technique in treatment of congenital hand anomalies: two case reports. Clin Orthop Relat Res. 1991;273:268-274

46. Mashiuz Z. Pseudarthrosis of the radius associated with neurofibromatosis. A case report. J Bone Joint Surg Am. 1977;59:977-978.

47. Bauer AS, Singh AK, Amanatullah D, et al. Free vascularized fibular transfer with langenskiöld procedure for the treatment of congenital pseudarthrosis of the forearm. Tech Hand Up Extrem Surg. 2013;17:144-150.

48. Mathoulin C, Gilbert A, Azze RG. Congenital pseudarthrosis of the forearm: treatment of six cases with vascularized fibular graft and a review of the literature. Microsurgery. 1993;14:252-259.

49. Fabry G, Lammens J, Van Melkebeek J, et al. Treatment of congenital pseudarthrosis with the Ilizarov technique. J Pediatr Orthop. 1988;8:67-70.

50. Masterson E, Earley MJ, Stephens MM. Congenital pseudarthrosis of the ulna treated by free vascularized fibular graft: a case report and review of methods of treatment. J Hand Surg. 1993;18B:285-288.

51. Beris AE, Lykissas MG, Kostas-Agnantis I, et al. Congenital pseudarthrosis of the radius treated with gradual distraction and 
free vascularized fibular graft: case report. J Hand Surg Am. 2010;35:406-411.

52. Suzuki O, Ishida O, Sunagawa T, et al. Congenital pseudoarthrosis of the ulna treated with a free vascularized fibular graft. Plast Reconstr Surg. 2005;115:1379-1384.

53. Durga Nagaraju K, Vidyadhara S, Raja D, et al. Congenital pseudarthrosis of the ulna. J Pediatr Orthop B. 2007;16:150-152.

54. Hadlow V. Congenital pseudarthrosis of the ulna: a case report. Aust New Zealand J Surg. 1979;49:100-104.

55. Allieu Y, Reckendorf GMZ, Chammas M, et al. Congenital pseudarthrosis of both forearm bones: long-term results of two cases managed by free vascularized fibular graft. J Hand Surg Am. 1999;24A:604-608.

56. Sellers DS, Sowa DT, Moore JR, et al. Congenital pseudarthrosis of the forearm. J Hand Surg. 1988;13:89-93.

57. Agha RA, Fowler AJ, Saeta A, et al. The SCARE statement: consensus-based surgical case report guidelines. Int J Surg. 2016; 34:180-186.

58. Agha RA, Fowler AJ, Rajmohan S, et al. Preferred reporting of case series in surgery; the PROCESS guidelines. Int J Surg. 2016;36 (pt A):319-323.

59. DiCaprio MR, Enneking WF. Fibrous dysplasia. Pathophysiology, evaluation, and treatment. J Bone Joint Surg Am. 2005;87:1848-1864.
60. Hefti F, Bollini G, Dungl P, et al. Congenital pseudarthrosis of the tibia: history, etiology, classification, and epidemiologic data. J Pediatr Orthop B. 2000;9:11-15.

61. Messiaen L, Yao S, Brems H, et al. Clinical and mutational spectrum of neurofibromatosis type 1-like syndrome. JAMA. 2009;302: 2111-2118.

62. Messiaen LM, Callens T, Mortier G, et al. Exhaustive mutation analysis of the NF1 gene allows identification of $95 \%$ of mutations and reveals a high frequency of unusual splicing defects. Hum Mutat. 2000;15:541-555.

63. Arai K, Toh S, Yasumura M, et al. One-bone forearm formation using vascularized fibula graft for massive bone defect of the forearm with infection: case report. J Reconstr Microsurg. 2001;17:151-155.

64. Horii E, Nakamura R, Koh S, et al. Surgical treatment for chronic radial head dislocation. J Bone Joint Surg Am. 2002;84-A:1183-1188.

65. Hurst LC, Dubrow EN. Surgical treatment of symptomatic chronic radial head dislocation: a neglected Monteggia fracture. $J$ Pediatr Orthop. 1983;3:227-230.

66. Boyd HB, Sage FP. Congenital pseudarthrosis of the tibia. $J$ Bone Joint Surg Am. 1958;40-A:1245-1270.

67. Hirayama T, Takemitsu Y, Yagihara K, et al. Operation for chronic dislocation of the radial head in children. Reduction by osteotomy of the ulna. J Bone Joint Surg Br. 1987;69:639-642. 